\title{
Laboratory studies for the momentum of liquid optimal impact on hydrocarbon formation
}

\author{
M. Ya. Khabibullin \\ Ufa State Petroleum Technological University \\ Branch of the University in the City of Oktyabrsky, \\ Oktyabrsky, Russian Federation \\ E-mail: m-hab@mail.ru
}

\author{
L. Z. Samigullina \\ Ufa State Petroleum Technological University \\ Branch of the University in the City of Oktyabrsky, \\ Oktyabrsky, Russian Federation \\ E-mail: m-hab@mail.ru
}

\author{
L. Z. Zainagalina \\ Ufa State Petroleum Technological University \\ Branch of the University in the City of Oktyabrsky, \\ Oktyabrsky, Russian Federation \\ E-mail: m-hab@mail.ru
}

\begin{abstract}
The paper presents laboratory studies of impulse water injection on the rock samples. A large number of experimental data were obtained. According to the experimental data, a regression analysis was carried out, on the basis of which qualitative correlations between factorial and resultant characteristics were revealed. Taking into account the mathematical analysis of the data obtained, graphical dependencies were constructed. As the fluid oscillation frequency increases, the amount of liquid passing through the sample of the porous medium increases, with the greatest value of fluid leakage through the rock samples reaching in the frequency range 600 ... 1000 Hertz.
\end{abstract}

Keywords - regression; analysis; factorial; result; attribute.

\section{INTRODUCTION}

One of the promising ways of oil recovery from hydrocarbon layers increasing and the produced water relative volume reducing is the method of liquid non-stationary pulsed into injection wells pumping and the effectiveness of which is confirmed by theoretical studies [1-13]. In this regard, there is a need to conduct laboratory studies to determine the optimal parameters for the method application.

\section{MATERIALS AND METHODS}

During the laboratory-experimental works, the research is conducted in two directions. In the first direction, leakage of liquid through the samples is investigated under different regime parameters. The technique is as follows. In the holder block, the layout of which is shown in Fig. 1, there are three chambers for the investigated samples installation, and all the chambers are interchangeable. In the holder, the investigated samples are installed, pre-placed in a rubber casing. Using a vibrator installed in the test chamber [2], the required frequency and fluid pressure fluctuation amplitude values are created which are recorded on photo paper. The liquid pressure value up to the test sample is regulated by means of a gate valve and its values are fixed according to the readings of the manometer. After the rubber casing of the test specimen in the body 4 rock pressure is created with the help of a hand operated oil pump and the fluid leakage through the test sample amount is measured volumetrically by withdrawing it from the holder through the outlet 9. Studies are carried out alternately for one, two and three test samples. The obtained values are represented in the form of graphical dependencies.

In the second direction of laboratory studies, the pressure fluctuation amplitude absorption magnitude is determined. For this purpose, strain gauges are installed in the outlets 9 , the signals from which are recorded on the photographic paper by the light-beam oscillograph. Creation of the necessary values of the operating parameters (the frequency and the pressure fluctuation amplitude, the pressure up to the test sample, the rock pressure) is carried out in the same sequence. The studies are carried out alternately for three samples, the strain gauges being installed after each test sample. When carrying out the research, sand of the following granulometric composition was used as a model of a porous medium: grains diameter is in the range of $0.21 \ldots 0.42 \mathrm{~mm}$. To prepare the samples, a mold was used whose internal dimensions are: the diameter is 24 $\mathrm{mm}$; the length is $40 \mathrm{~mm}$. The sand was sieved, washed with distilled water beforehand, and compacted in a mold using a press with a final force of $1200 \mathrm{~N}$. The test was carried out using three pressure values in the test chamber $\mathrm{P}=1.0 ; 1.5$; 2.0 $\mathrm{MPa}$, and at each pressure value in the test chamber, the following values of the external pressure on the samples $\mathrm{P}_{\mathrm{r}}=$ 0.5 were created; $1.4 ; 2.3 \mathrm{MPa}$. The liquid oscillation frequency was created by means of vibrators, the value of which for all the experiments was of the same values: 200, $400,600,800,1000,1200 \mathrm{~Hz}$, the error being no more than \pm $5 \%$. The results of laboratory studies are presented in Table 1, 2,3 . 


\section{RESULTS AND DISCUSSIONS}

According to experimental data, the regression analysis was carried out, on the basis of which the qualitative correlations between the factorial and the resultant descriptors were revealed.

For all three cases, the matrix of the full factor experiment $2^{3}$ [3] was made. The regression equations represented the dependence of $q=\varphi\left(f, P, P_{r}\right)$ in linear form. The significance of the regression coefficients was verified with the help of Student's t-test and in all three cases the combination of $f P$ and $f P P_{r}$ factors does not affect the resultant descriptor.

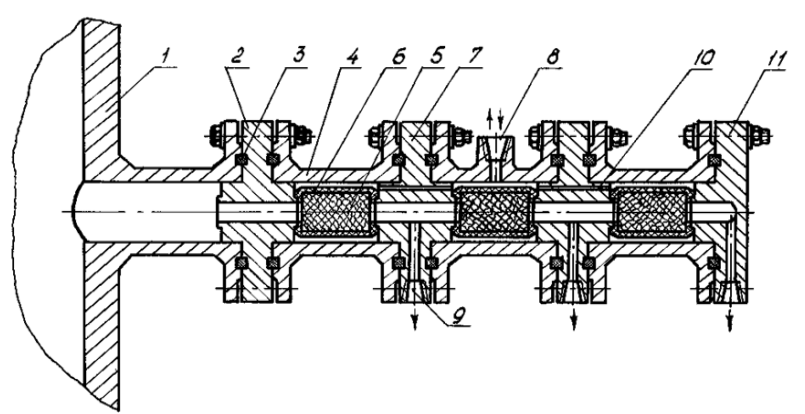

1 - test string; 2 - thrust flange; 3 - sealing cup; 4 - body; 5 - specimen under investigation; 6 - rubber casing; 7 - intermediate flange; 8 - outlet for connection with hand operated oil pump; 9 - outlets for liquid volume measuring and strain gauges installation; 10 - channels for the inner cavity of the bodies interconnection; 11 - end flange.

Fig. 1. Holder Block

TABLE I. FLUID LEAKAGE AMOUNT THROUGH ONE SAMPLE OF A POROUS MEDIUM $\left(Q \times 10^{-4} \mathrm{M}^{3} / \mathrm{SEC}\right.$. $)$

\begin{tabular}{|c|c|c|c|c|c|c|c|c|c|}
\hline \multirow{2}{*}{$\begin{array}{c}\text { Liquid } \\
\text { oscillation } \\
\text { frequency } \\
\quad f, \mathrm{~Hz}\end{array}$} & \multicolumn{3}{|c|}{$P_{1}$} & \multicolumn{3}{|c|}{$P_{2}$} & \multicolumn{3}{|c|}{$P_{3}$} \\
\hline & $P_{r l}$ & $P_{r 2}$ & $\boldsymbol{P}_{r 3}$ & $P_{r 1}$ & $P_{r 2}$ & $\boldsymbol{P}_{r 3}$ & $P_{r 1}$ & $P_{r 2}$ & $\boldsymbol{P}_{r 3}$ \\
\hline 200 & 0.0323 & 0.0312 & 0.0301 & 0.0418 & 0.0397 & 0.0372 & 0.0462 & 0.0433 & 0.0418 \\
\hline 400 & 0.0434 & 0.0421 & 0.0413 & 0.0486 & 0.0413 & 0.0396 & 0.0511 & 0.0495 & 0.0482 \\
\hline 600 & 0.0562 & 0.0522 & 0.0502 & 0.0598 & 0.0564 & 0.0549 & 0.0623 & $\overline{0.0601}$ & 0.0588 \\
\hline 800 & 0.0687 & 0.0603 & 0.0596 & 0.0712 & 0.0676 & 0.0661 & 0.0766 & 0.0722 & 0.0703 \\
\hline 1000 & $\overline{0.0623}$ & $\overline{0.0613}$ & 0.0584 & $\overline{0.0716}$ & 0.0669 & 0.0656 & 0.0754 & 0.0713 & $\overline{0.0689}$ \\
\hline 1200 & $\overline{0.0618}$ & $\overline{0.0592}$ & $\overline{0.0580}$ & 0.0704 & $\overline{0.0663}$ & $\overline{0.0650}$ & $\overline{0.0751}$ & $\overline{0.0711}$ & $\overline{0.0682}$ \\
\hline 1400 & 0.0611 & 0.0598 & 0.0563 & 0.0693 & 0.0654 & 0.0632 & 0.0741 & 0.0709 & 0.0682 \\
\hline 1600 & 0.0602 & 0.0576 & 0.0560 & 0.0690 & 0.0658 & 0.0614 & 0.0733 & 0.0686 & 0.0680 \\
\hline
\end{tabular}

TABLE II. FLUID LEAKAGE AMOUNT THROUGH TWO SAMPLES OF A POROUS MEDIUM $\left(Q \rtimes 0^{-5} \mathrm{M}^{3} / \mathrm{SEC}\right.$. $)$

\begin{tabular}{|c|c|c|c|c|c|c|c|c|c|}
\hline \multirow{2}{*}{$\begin{array}{c}\text { Liquid } \\
\text { oscillation } \\
\text { frequency } \\
\quad f, \mathrm{~Hz}\end{array}$} & \multicolumn{3}{|c|}{$P_{1}$} & \multicolumn{3}{|c|}{$P_{2}$} & \multicolumn{3}{|c|}{$P_{3}$} \\
\hline & $\boldsymbol{P}_{r 1}$ & $\boldsymbol{P}_{r 2}$ & $\boldsymbol{P}_{r 3}$ & $P_{r 1}$ & $\boldsymbol{P}_{r 2}$ & $\boldsymbol{P}_{r 3}$ & $\boldsymbol{P}_{r 1}$ & $\boldsymbol{P}_{r 2}$ & $\boldsymbol{P}_{r 3}$ \\
\hline 200 & 0.172 & 0.141 & 0.120 & 0.211 & 0.201 & 0.186 & 0.267 & 0.229 & 0.201 \\
\hline 400 & 0.218 & 0.168 & 0.141 & 0.262 & 0.246 & 0.211 & 0.310 & 0.269 & 0.248 \\
\hline 600 & 0.264 & 0.201 & 0.183 & 0.293 & 0.282 & 0.265 & 0.345 & 0.297 & 0.282 \\
\hline
\end{tabular}

TABLE II., cont.

\begin{tabular}{|c|c|c|c|c|c|c|c|c|c|}
\hline 800 & 0.297 & 0.242 & 0.212 & 0.324 & 0.283 & 0.272 & 0.366 & 0.312 & 0.303 \\
\hline 1000 & 0.302 & 0.241 & 0.210 & 0.304 & 0.280 & 0.264 & 0.368 & 0.312 & 0.294 \\
\hline 1200 & 0.296 & 0.232 & 0.201 & 0.286 & 0.279 & 0.264 & 0.346 & 0.311 & 0.291 \\
\hline 1400 & 0.286 & 0.234 & 0.193 & 0.276 & 0.271 & 0.263 & 0.337 & 0.305 & 0.288 \\
\hline 1600 & 0.272 & 0.221 & 0.191 & 0.264 & 0.265 & 0.258 & 0.331 & 0.298 & 0.286 \\
\hline
\end{tabular}

TABLE III. FLUID LEAKAGE AMOUNT THROUGH THREE SAMPLES OF A POROUS MEDIUM $\left(Q \rtimes 0^{-6} \mathrm{M}^{3} / \mathrm{SEC}.\right)$

\begin{tabular}{|c|c|c|c|c|c|c|c|c|c|}
\hline $\begin{array}{c}\text { Liquid } \\
\text { oscillation } \\
\text { frequency } \\
\boldsymbol{f}, \mathbf{H z}\end{array}$ & \multicolumn{3}{|c|}{$\boldsymbol{P}_{\boldsymbol{1}}$} & \multicolumn{3}{c|}{$\boldsymbol{P}_{\mathbf{2}}$} & \multicolumn{3}{c|}{$\boldsymbol{P}_{\mathbf{3}}$} \\
\cline { 2 - 10 } & $\boldsymbol{P}_{\boldsymbol{r} \mathbf{1}}$ & $\boldsymbol{P}_{\boldsymbol{r} \mathbf{2}}$ & $\boldsymbol{P}_{\boldsymbol{r} \mathbf{3}}$ & $\boldsymbol{P}_{\boldsymbol{r} \mathbf{1}}$ & $\boldsymbol{P}_{\boldsymbol{r} \mathbf{2}}$ & $\boldsymbol{P}_{\boldsymbol{r} \mathbf{3}}$ & $\boldsymbol{P}_{\boldsymbol{r} \boldsymbol{1}}$ & $\boldsymbol{P}_{\boldsymbol{r} \mathbf{2}}$ & $\boldsymbol{P}_{\boldsymbol{r} 3}$ \\
\hline 200 & 0.882 & 0.863 & 0.845 & 0.925 & 0.897 & 0.872 & 1.002 & 0.981 & 0.962 \\
\hline 400 & 0.928 & 0.894 & 0.868 & 0.966 & 0.932 & 0.912 & 1.035 & 0.019 & 0.989 \\
\hline 600 & 0.967 & 0.936 & 0.921 & 0.999 & 0.987 & 0.985 & 1.086 & 1.065 & 1.034 \\
\hline 800 & 0.983 & 0.966 & 0.945 & 1.031 & 0.982 & 0.964 & 1.121 & 1.093 & 1.051 \\
\hline 1000 & 0.972 & 0.963 & 0.936 & 1.020 & 0.984 & 0.963 & 1.116 & 1.077 & 1.053 \\
\hline 1200 & 0.973 & 0.942 & 0.936 & 1.004 & 0.976 & 0.956 & 1.100 & 1.076 & 1.052 \\
\hline 1400 & 0.967 & 0.940 & 0.925 & 1.006 & 0.964 & 0.948 & 1.094 & 1.061 & 1.044 \\
\hline 1600 & 0.956 & 0.932 & 0.921 & 0.986 & 0.957 & 0.943 & 1.093 & 1.052 & 1.033 \\
\hline
\end{tabular}

The hypothesis on the adequacy of the proposed models was tested using Fischer's F-criterion. The regression equations are as follows:

$$
\begin{aligned}
& q_{l}=(-0.000324+0.00000983 f+ \\
& +0.0271 P+0.0301 P_{r}-0.0125 P \rtimes_{r}- \\
& \left.-0.00000494 f \bigotimes_{r}\right) \rtimes 0^{-4} ; \\
& q_{2}=(0.08213+0.000021 f+0.09038 P+ \\
& +0.09735 P_{r}-0.0447 P \rtimes_{r}- \\
& \left.-0.000015 f \bigotimes_{r}\right) \rtimes 0^{-5} ; \\
& q_{3}=(-0.78906+0.000028 f+0.09696 P+ \\
& +0.10805 P_{r}-0.0489 P \rtimes_{r}- \\
& \left.-0.00002 f \rtimes_{r}\right) \rtimes 0^{-6} ;
\end{aligned}
$$

The experimental graphical dependencies $q=\varphi(f)$ (when $P$ $=1 \mathrm{MPa}$ and $P_{r}=0.5 \mathrm{MPa}$ ) are shown in the Fig. 2, 3, 4. After analyzing the results, it was revealed that with the increase in the fluid fluctuations frequency the amount of fluid passing through the porous medium sample increases, with the highest value $q$ reaching in the frequency range of $600 \ldots 1000 \mathrm{~Hz}$. As to the value of pressures, namely their influence on $q$, the conducted laboratory studies confirm the theoretical results of the majority of authors. 


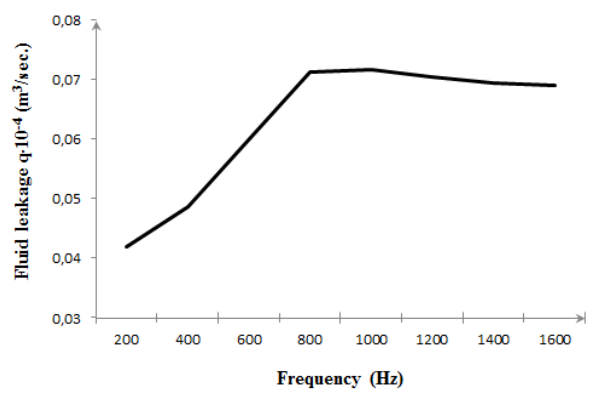

Fig. 2. Fluid leakage through one sample of the porous medium dependence from fluid oscillation frequency $(f, H z)$ when $P=1 \mathrm{MPa}, P_{r}=0.5 \mathrm{MPa}$.

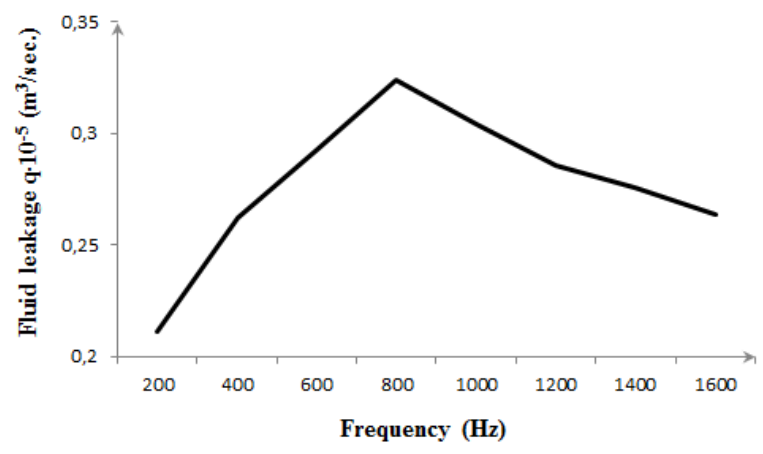

Fig. 3. Fluid leakage through two samples of the porous medium dependence from fluid oscillation frequency $(f, H z)$ when $P=1 \mathrm{MPa}, P_{r}=0.5 \mathrm{MPa}$.

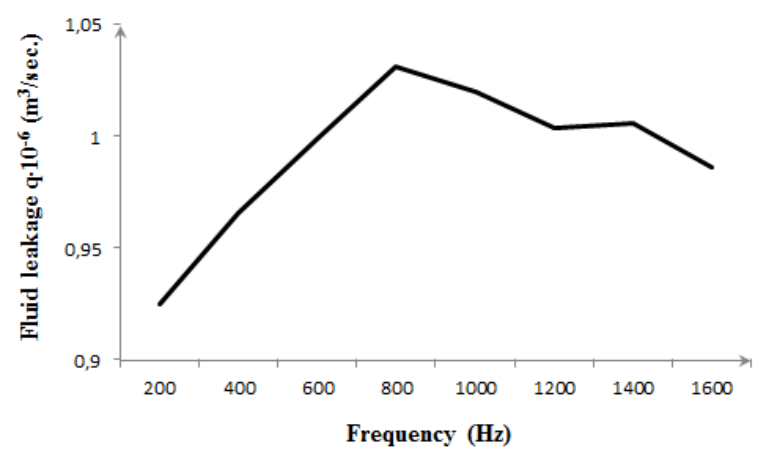

Fig. 4. Fluid leakage through three samples of the porous medium dependence from fluid oscillation frequency $(f, H z)$ when $P=1 \mathrm{MPa}, P_{r}=0.5$ MPa.

During the second stage of laboratory studies, the preparation and composition of the porous medium samples were similar to the first stage. The fluid pressure change amplitude was recorded after each sample. Experiments were carried out at a liquid pressure up to the samples of $2.0 \mathrm{MPa}$, liquid fluctuations frequency of $1000 \mathrm{~Hz}$, and the pressure on samples value was $1.0 ; 2.0 ; 3.0 \mathrm{MPa}$. The results are shown in Fig. 5.

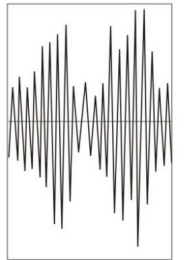

in the test string

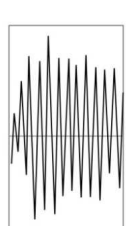

$1^{\text {st }}$ sample

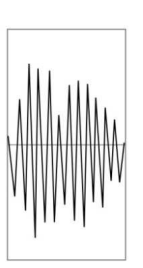

$1^{\text {st }}$ sample

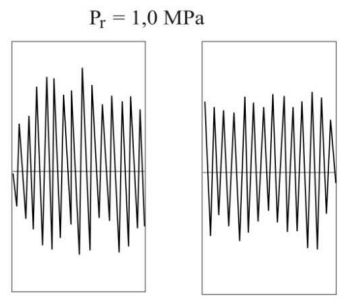

$2^{\text {nd }}$ sample

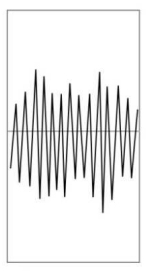

$3^{\mathrm{d}}$ sample

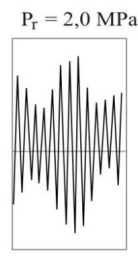

$2^{\text {nd }}$ sample

$\mathrm{P}_{\mathrm{r}}=3,0 \mathrm{MPa}$

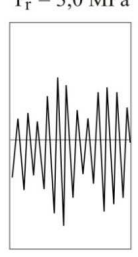

$2^{\text {nd }}$ sample
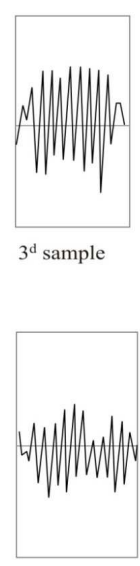

$3^{\mathrm{d}}$ sample

Fig. 5. Pressure fluctuations amplitude changing for different external pressure values on the porous medium samples.
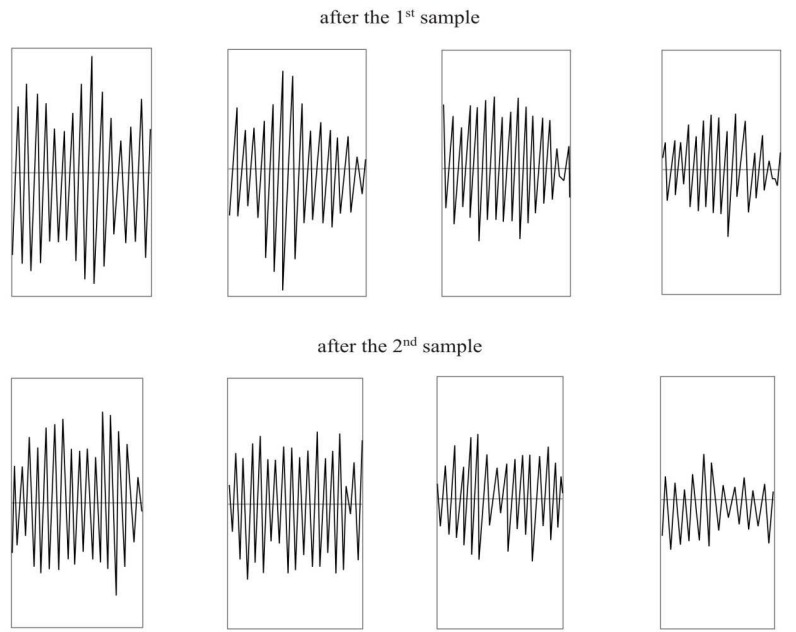

after the $2^{\text {nd }}$ sample
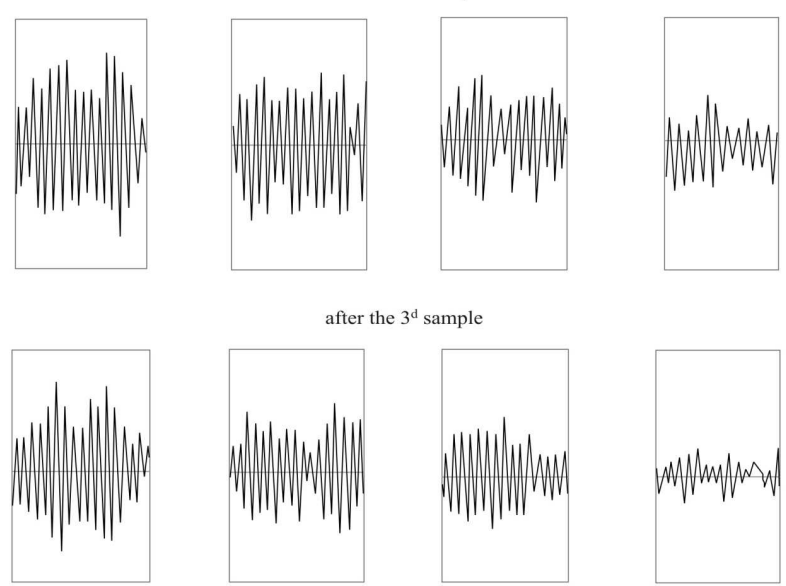

Fig. 6. Pressure fluctuation amplitude change at different liquid oscillation frequency values $(\mathrm{P}=2.0 \mathrm{MPa}, \operatorname{Pr}=1.5 \mathrm{MPa})$. 


\section{CONCLUSION}

On the basis of a detailed analysis of the pressure fluctuation amplitude variation, the following conclusions can be drawn. With the oscillations penetration depth increasing the pressure fluctuations amplitude absorption corresponds to linear reduction, and with rock pressure increase the linear change of absorption is distorted.

Fig. 6 shows the results of pressure fluctuation amplitude changes at different fluid fluctuations frequency values (at $P=$ 2.0MPa and $P_{r}=1.5 \mathrm{MPa}$ ). The obtained data, after their comparison, allow us to draw the following conclusion. The smallest absorption is typical for the oscillation frequency in the range of $0 \ldots 1000 \mathrm{~Hz}$.

\section{References}

[1] M. Ya. Khabibullin, R. I. Suleimanov, D. I. Sidorkin and I. G. Arslanov, "Parameters of Damping of Vibrations of Tubing String in the Operation of Bottomhole Pulse Devices," Chem Petrol Eng, vol. 53, pp. 378-384, 2017. https://doi.org/10.1007/s10556-017-0350-6

[2] M. Ya. Khabibullin, I. G. Arslanov, and R. Ya. Abdyukova" Laboratory installation used for researching of fluids pulsed injection into a formation," Equipment and technologies for oil and gas complex, 2, pp.14-16, April 2016.

[3] Korn G A, Korn T M. Mathematical Handbook for Scientists and Engineers: Definitions, Theorems, and Formulas for Reference and Review. Moscow: Nauka, 1984.

[4] R.M. Shaidullina, A.F. Amirov, V.S. Muhametshin and K.T. Tyncherov, "Designing economic socialization system in the educational process of technological university," European Journal of Contemporary Education, no. 6 (1), pp. 149-158, 2017. DOI: 10.13187/ejced.2017.1.1494

[5] N.Y. Golovina, L.G. Akhmetov, A.N. Vikharev and I.G. Arslanov, "Analysis on compressor blading conditions of helicopter's gas-Turbine engine working in polluted environment," International Journal of Applied Engineering Research, vol. 12, pp. 293-296, 2017.
[6] G.R. Igtisamova and N.O. Kovalev "Reliability evaluation for improved screw dies of coiled tubing unit injector," Tribology in Industry, vol. 39, pp. 45-49, 2017

[7] M.V. Goryunova, L.S. Kuleshova and A.I. Khakimova, "Application of signal analysis for diagnostics," International Conference on Industrial Engineering, Applications and Manufacturing (ICIEAM) (Saint Petersburg, 16-19 May 2017) / the team of authors, SPb.: IEEE, 2017. DOI: 10.1109/ICIEAM.2017.8076487

[8] V.V. Mukhametshin, "Efficiency estimation of nanotechnologies applied in constructed wells to accelerate field development," Nanotechnologies in Construction, vol. 10, no. 1, pp. 113-131, 2018. DOI: 10.15828/20758545-2018-10-1-113-131

[9] K.T. Tyncherov, V.Sh. Mukhametshin and L.B. Khuzina, "Method to Control and Correct Telemetry Well Information in the Basis of Residue Number System," Journal of Fundamental and Applied Sciences, vol. 9, no. (2S), pp. 1370-1374, 2017. DOI: 10.4314/jfas.v9i2s.848

[10] G.A. Teptereva, G.V. Konesev, R.A. Ismakov, E.A. Kantor and T.D. Dikhtyar, "Obtaining drill reagents by modification of neutral-sulphite alkali phosphonic compounds," Bulletin of the Tomsk Polytechnic University, Geo Assets Engineering, vol. 328, pp. 94-101, 2017.

[11] L.A. Kovaleva, R.Z. Minnigalimov, R.R. Zinnatullin, V.N. Blagochinnov and A.I. Mullayanov, "Study of integrated effects microwave electromagnetic radiation in the field of centrifugal forces on the water-oil emulsion," Neftyanoe Khozyaystvo - Oil Industry, vol.2, pp. 100-102, 2017.

[12] A. Davletbaev, V. Kireev, L. Kovaleva, A. Zainullin, R. Minnigalimov, "Cold heavy oil production and production by radio-frequency electromagnetic radiation: Comparative numerical study," AIP Conference Proceedings International Conference of Computational Methods in Sciences and Engineering, ICCMSE 2016, vol. 1790, pp. 150021,2016

[13] V.N. Polyakov, Yu.V. Zeigman, Yu.A. Kotenev, V.V. Mukhametshin, Sh.Kh. Sultanov and A.P. Chizhov, "System solution for technological problems of well construction completion," Nanotechnologies in Construction, Vol. 10, no. 1, pp. 72-87, 2018. DOI: 10.15828/2075$8545-2018-10-1-72-87$ 